Angew Chem Int Ed Engl. 2016 May 4; 55(19): 5819-5823. doi:10.1002/anie.201600235.

\title{
Iridium-Catalyzed Diastereoselective and Enantioselective Allylic Substitutions with Acyclic a-Alkoxy Ketones ${ }^{* *}$
}

\author{
Xingyu Jiang, Wenyong Chen, and Prof. John F. Hartwig \\ Department of Chemistry, University of California, Berkeley, CA 94720 (USA) and Division of \\ Chemical Sciences, Lawrence Berkeley National Laboratory, Berkeley, California 94720, United \\ States
}

John F. Hartwig: jhartwig@berkeley.edu

\begin{abstract}
The asymmetric alkylation of acyclic ketones is a longstanding challenge in organic synthesis. We report diastereoselective and enantioselective allylic substitutions with acyclic a-alkoxy ketones catalyzed by a metallacyclic iridium complex to form products with contiguous stereogenic centers derived from the nucleophile and electrophile. These reactions occur between allyl methyl carbonates and unstabilized copper(I) enolates generated in situ from acyclic a-alkoxy ketones. The resulting products can be readily converted to enantioenriched tertiary alcohols and tetrahydrofuran derivatives without erosion of enantiomeric purity.
\end{abstract}

\section{Graphical Abstract}

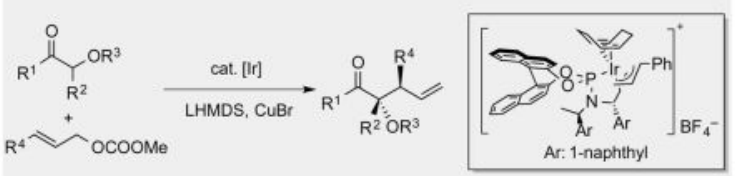

The asymmetric alkylation of acyclic ketones is a longstanding synthetic challenge. We report diastereoselective and enantioselective allylic substitutions with acyclic a-alkoxy ketones catalyzed by a metallacyclic iridium complex to form products containing two contiguous stereogenic centers, one derived from the nucleophile and one from the electrophile. These reactions occur between allyl methyl carbonates and unstabilized copper(I) enolates generated in situ from acyclic a-alkoxy ketones. The resulting products can be readily converted to enantioenriched tertiary alcohols and tetrahydrofuran derivatives without erosion of ee.

\section{Keywords}

alkylation; asymmetric catalysis; ketones; iridium; diastereoselectivity

\footnotetext{
** Financial support provided by the Director, Office of Science, of the U.S. Department of Energy under contract no. DEAC02-05CH11231 and the NIH-NIGMS (GM-55382).

Correspondence to: John F. Hartwig, jhartwig@berkeley . edu.
} 
Transition metal-catalyzed asymmetric allylation of enolates serves as an efficient and reliable method to construct carbon-carbon bonds with high levels of asymmetric induction. ${ }^{[1]}$ The majority of these reactions form products containing a single stereocenter from a prochiral enolate as the nucleophile or a prochiral allylic compound as the electrophile. If both nucleophile and electrophile are prochiral, synthetically valuable dyads containing contiguous stereocenters could be assembled in a catalytic and stereoselective fashion. ${ }^{[2]}$ However, this transformation is challenging because a new bond needs to be formed between two sterically hindered prochiral carbons with control of both absolute and relative configurations.

Metallacyclic iridium complexes catalyze allylic substitutions with a variety of carbon and heteroatom nucleophiles regio- and enantioselectively. ${ }^{[1 b, 3]}$ Although reactions have been reported between prochiral enolates and prochiral electrophiles to afford products containing vicinal tetra-substituted and tertiary stereocenters with excellent diastereo- and enantioselectivity, reactions with unstabilized, acyclic, prochiral ketones have not been reported. ${ }^{[4]}$ The main challenge facing this transformation results from the lack of control of the geometry of the unstabilized enolate of an a-branched acyclic ketone. In contrast to cyclic enolates, the backbone of the nucleophile does not dictate the geometry. Also, because a-branched, acyclic ketones do not readily form enamines, the use of amine auxiliaries has not been effective to control the geometry. ${ }^{[5]}$

In the presence of suitable metal cations, acyclic carbonyl compounds bearing aheteroatoms form enolates with a defined geometry created by chelation. This structure has been exploited for the allylation of glycine derivatives. ${ }^{[6]}$ However, these reactions occurred with low diastereoselectivity when forming products containing adjacent tetra-substituted and tertiary stereocenters. ${ }^{[6 a]}$ With the same strategy, Evans and co-workers achieved diastereoselective allylations of a-hydroxy, as well as a-alkoxy or a-siloxy acetophenone catalyzed by an achiral rhodium catalyst. ${ }^{[7]}$ However, only products containing adjacent tertiary and tri-substituted stereocenters bearing oxygen were formed, and no enantioselective transformation was reported. We envisioned that this strategy could be followed to achieve the enantioselective allylation of unstabilized ketones with cyclometallic iridium catalysts we developed. ${ }^{[8]}$

Herein, we report diastereo- and enantioselective allylic alkylations with unstabilized enolates of acyclic a-alkoxy ketones catalyzed by iridium complex $\mathbf{3}$ (Scheme 1). The geometry of the enolates is controlled through chelation in the presence of a copper(I) cation. These reactions form, with high diastereo- and enantioselectivity, products containing vicinal oxygen-bearing tetra-substituted and tertiary stereocenters. Products containing an $O$-MOM (methoxymethyl) group on the tertiary alcohol were formed in good yield with high $d r$ and $e e$, and these products can be readily converted to tertiary alcohols and tetrahydrofuran (THF) derivatives without erosion of enantiomeric purity.

To assess the potential of developing an iridium-catalyzed allylation of an acyclic ketone enolate, we conducted the reactions between $O$-methyl benzoin (1a) and methyl cinnamyl carbonate (2a) (Table 1). Treatment of 1a and 2a with Ir complex $\mathbf{3}$ in the presence of LHMDS at $5{ }^{\circ} \mathrm{C}$ for $12 \mathrm{~h}$ furnished the branched product 4 aa in $95 \%$ yield (combined yield 
of two diastereoisomers), but with a low $d r$ of 2.0:1 (entry 1). The reaction conducted after addition of $\mathrm{LiCl}^{[40]}$ to the lithium enolate gave the product with a lower $d r$ of $1: 1.1$, slightly favoring the formation of the other diastereoisomer (entry 2). The reaction with added $\mathrm{ZnCl}_{2}{ }^{[6]}$ afforded 4aa with excellent diastereoselectivity (16:1 $d r$, entry 3), albeit in a lower yield of $72 \%$. In contrast, the reaction conducted with added CuI occurred with a higher diastereomeric ratio to 5.7:1 while maintaining excellent conversion to yield 4 aa in $97 \%$ yield (entry 4). Similarly, Evans and coworkers observed higher diastereoselectivity with the copper(I) enolate of a-hydroxy acetophenone derivatives than with the corresponding lithium enolate. ${ }^{[7]}$

Because the anion of the copper(I) salt could influence the transmetalation, we further evaluated a series of copper(I) salts. Reactions conducted with added $\mathrm{CuBr}$ occurred with a higher diastereomeric ratio of 14:1 with an excellent ee of 92\% (entry 6). The major diastereoisomer was isolated in $93 \%$ yield (see SI for details). Reactions with other copper(I) additives, such as $\mathrm{CuCl}, \mathrm{CuCN}, \mathrm{CuOAc}$ or $\mathrm{CuSCN}$, occurred in significantly lower yield (58\%, entry 5) or with lower $d r\left(1.5-2.5: 1\right.$, entries 7-9). ${ }^{[9]}$

The identity of the cation of the anionic base was crucial to obtaining high yields and diastereoselectivities. Reactions conducted with KHMDS instead of LHMDS afforded only $42 \%$ yield of 4aa with a significantly lower $d r$ of 2.7:1 (entry 10). Reactions conducted with one equivalent of copper in place of two equivalents led to excellent reactivity and afforded the product in identical $d r$ and ee (entry 11 ), but reactions with 0.5 equiv occurred with lower $d r$ (although slightly higher ee) as shown in entry $12 .{ }^{[10]}$ In all cases, the branched product was obtained exclusively. Reactions run with $\mathrm{CuBr}_{2}$ as additive gave no product, indicating the critical role of the copper(I) cation in this reaction, rather than a copper(II) cation that might be formed by disproportionation or oxidation of copper(I) salt (entry 13).

The scope of the allylic electrophiles that underwent the Ir-catalyzed allylic substitution with acyclic a-alkoxy ketones is summarized in Table 2. Various para-substituted cinnamyl carbonates are suitable electrophiles. Electron-neutral (4ab), electron-donating (4ac) and electron-withdrawing (4ah, 4ai) functional groups on the cinnamyl aryl ring were all tolerated in this reaction, and the corresponding products were formed in excellent yield ( $\geq 94 \%$ ) with high $d r(\geq 10: 1)$ and ee ( $\geq 90 \%$ ). Cinnamyl carbonates bearing halogens at the para- or meta-position reacted cleanly, furnishing 4ad-ag in $\geq 92 \%$ yield, $\geq 12: 1 d r$ and $\geq 91 \%$ ee. ${ }^{[1]}$ The absolute stereochemistry of $\mathbf{4 a g}$ was established by single crystal X-ray diffraction.

The reaction also occurred with allylic carbonates containing heteroaryl, alkenyl and alkyl substituents. The reaction of thienyl carbonate $\mathbf{2 k}$ afforded $\mathbf{4 a k}$ in high yield with excellent diastereo- and enantioselectivity (>99\%, >20:1 $d r$, 92\% ee). Methyl sorbyl carbonate (2l) reacted to form product 4al in 75\% yield with $>20: 1 d r$ and $94 \%$ ee. Even the simple crotyl carbonate $(\mathbf{2 m})$ reacted to form product 4am in good yield, although the $d r$ and $e e(71 \%, 8: 1$ $d r$ and $88 \%$ ee) were slightly lower than those with aryl-substituted allylic carbonates.

The scope of the acyclic a-alkoxy ketones that underwent the Ir-catalyzed allylation is summarized in Table 3. ${ }^{[12-13]}$ MOM (1b), MEM (methoxyethoxymethyl, 1c), and PMB 
(para-methoxybenzyl, 1d) protected benzoins underwent allylation in high yield with excellent diastereo- and enantioselectivity. The reaction between $O$-MOM benzoin $\mathbf{1 b}$ and cinnamyl carbonate 2a required a higher catalyst loading of $4 \mathrm{~mol} \%$ to reach full conversion within 12 hours. Several acyclic $O$-Me benzoin derivatives bearing identical substituents at both aryl rings, such as $\mathbf{1 e}$ and $\mathbf{1 f}$, as well as their $O$-MOM analogues $\mathbf{1 i}$ and $\mathbf{1 j}$ were suitable for this transformation (4ea, 4fa, 4ic and 4jk, $\geq 84 \%, \geq 7: 1 d r, \geq 94 \%$ ee).

The reactions with nucleophiles derived from non-symmetrical benzoins were also examined. Benzoin 1g, bearing a thienyl group, underwent allylation in quantitative yield with excellent $d r$ of 15:1 and 96\% ee (4ga). Benzoin analogue $\mathbf{1 h}$, containing an $i$-butyl group, reacted with methyl cinnamyl carbonate $\mathbf{2 a}$ in low yield of $38 \%$ and low branched/ linear selectivity of 4:1 (5:1 $d r$ for the branched product) ${ }^{[14]}$ However, the identical reaction with the less reactive cinnamyl acetate as the electrophile afforded branched product 4 ha exclusively in high yield ( $74 \%$, isolated yield of the major diastereomer) with acceptable diastereoselectivity and excellent enantioselectivity $(6: 1 \mathrm{dr},>99 \% \mathrm{ee})$.

Allylation products containing an $O$-MOM group on the tertiary alcohol were readily transformed to enantioenriched tertiary alcohols $\mathbf{5}$ containing adjacent tertiary stereogenic centers (Table 2). Deprotection of $\mathbf{4 b a}$ by reaction with acidic Dowex-50W-X8 resin ${ }^{[15]}$ (step i) afforded the corresponding alcohols $5 \mathbf{b a}$ in quantitative yield without any erosion of enantiomeric purity. The synthetic value of these allylated benzoin derivatives was further demonstrated by their transformation into highly substituted THF derivatives. Hydroboration of 4 ba with 9-BBN, followed by oxidation (step ii), yielded the terminal alcohol, which was subsequently converted to the corresponding tosylate (step iii). Removal of the MOM protecting group (step i) afforded the free tertiary alcohol, which underwent a 5-exo-tet cyclization in situ to furnish THF derivative $6 \mathbf{b a}$ in $45 \%$ yield over 3 steps.

These synthetic sequences were also applied to allylation products bearing different substituents $\mathrm{R}^{1}, \mathrm{R}^{2}$ and $\mathrm{R}^{3}$. In all cases, substrates 4ic $\left(\mathrm{R}^{1}=\mathrm{R}^{2}=4\right.$-tol, $\mathrm{R}^{3}=4$-anisyl), 4jk $\left(\mathrm{R}^{1}=\mathrm{R}^{2}=4\right.$-anisy, $\mathrm{R}^{3}=2$-thienyl) and $\mathbf{4 k m}\left(\mathrm{R}^{1}=\mathrm{Ph}, \mathrm{R}^{2}=2\right.$-thienyl and $\left.\mathrm{R}^{3}=\mathrm{Me}\right)$ afforded the corresponding tertiary alcohols $\mathbf{5 i c}, \mathbf{5 j} \mathbf{k}$ and $\mathbf{5} \mathbf{k m}$ in high yield without erosion of enantiomeric purity. Similarly, the corresponding THF derivatives $6 \mathbf{i c}, \mathbf{6 j k}$ and $\mathbf{6} \mathbf{k m}$ were obtained in high enantiomeric purity.

The olefin moiety is a useful precursor to many functional groups. For example, ozonolysis, hydrogenation and the combination of hydroboration and oxidation of the products of allylation 4aa afforded aldehyde 7aa, ketone 8aa, and primary alcohol 9aa, respectively, in high yields without erosion of enantiomeric purity (Scheme 2).

In summary, we have developed Ir-catalyzed diastereo- and enantioselective allylic substitutions with unstabilized copper(I) enolates of acyclic a-alkoxy ketones. Employing metallacyclic complex 3 as the catalyst, LHMDS as the base and $\mathrm{CuBr}$ as the additive, allylation reactions gave the products containing vicinal tetra-substituted and tertiary stereocenters in high yield with excellent $d r$ and ee. The geometry of the enolates is controlled by chelation in the presence of a copper(I) cation. The synthetic utility of this method was demonstrated by the synthesis of enantioenriched THF derivatives and tertiary

Angew Chem Int Ed Engl. Author manuscript; available in PMC 2017 May 04. 
alcohols containing adjacent tertiary stereogenic centers. Studies to gain insight into the origin of diastereoselectivity in this reaction are ongoing in our laboratories.

\section{Supplementary Material}

Refer to Web version on PubMed Central for supplementary material.

\section{References}

1. a) Ding, CH.; Hou, XL. Comprehensive Organic Synthesis II. 2. Knochel, P., editor. Elsevier; Amsterdam: 2014. p. 648b) Hartwig JF, Stanley LM. Acc Chem Res. 2010; 43:1461. [PubMed: 20873839] c) Liu Y, Han SJ, Liu WB, Stoltz BM. Acc Chem Res. 2015; 48:740. [PubMed: 25715056] d) Lu Z, Ma S. Angew Chem Int Ed. 2008; 47:258.e) Oliver S, Evans PA. Synthesis. 2013; 45:3179.f) Trost BM, Van Vranken DL. Chem Rev. 1996; 96:395. [PubMed: 11848758]

2. a) Christoffers, J.; Baro, A. Quaternary Stereocenters: Challenges and Solutions for Organic Synthesis. Wiley-VCH; Weinheim: 2005. b) Douglas CJ, Overman LE. Proc Natl Acad Sci USA. 2004; 101:5363. [PubMed: 14724294] c) Quasdorf KW, Overman LE. Nature. 2014; 516:181. [PubMed: 25503231] d) Trost BM, Crawley ML. Chem Rev. 2003; 103:2921. [PubMed: 12914486] e) Trost BM, Jiang C. Synthesis. 2006:369.f) Yus M, González-Gómez JC, Foubelo F. Chem Rev. 2013; 113:5595. [PubMed: 23540914]

3. a) Hartwig JF, Pouy MJ. Top Organomet Chem. 2011; 34:169.b) Helmchen, G. Iridium Complexes in Organic Synthesis. Wiley-VCH; Weinheim: 2009. p. 211c) Helmchen G, Dahnz A, Dubon P, Schelwies M, Weihofen R. Chem Commun. 2007:675.d) Liu W-B, Xia J-B, You S-L. Top Organomet Chem. 2012; 38:155.e) Teichert JF, Feringa BL. Angew Chem Int Ed. 2010; 49:2486.f) Tosatti P, Nelson A, Marsden SP. Org Biomol Chem. 2012; 10:3147. [PubMed: 22407450]

4. Chen W, Chen M, Hartwig JF. J Am Chem Soc. 2014; 136:15825. [PubMed: 25337972] Chen W, Hartwig JF. J Am Chem Soc. 2013; 136:377. [PubMed: 24295427] Chen W, Hartwig JF. J Am Chem Soc. 2013; 135:2068. [PubMed: 23286279] Liu WB, Reeves CM, Virgil SC, Stoltz BM. J Am Chem Soc. 2013; 135:10626. [PubMed: 23829704] . For reactions of a-branched aldehydes, see: Krautwald S, Sarlah D, Schafroth MA, Carreira EM. Science. 2013; 340:1065. [PubMed: 23723229] Krautwald S, Schafroth MA, Sarlah D, Carreira EM. J Am Chem Soc. 2014; 136:3020. [PubMed: 24506196] Sandmeier T, Krautwald S, Zipfel HF, Carreira EM. Angew Chem Int Ed. 2015; 54:14363.. For reactions of stabilized enolates of $\beta$-ketoesters, see: Liu WB, Reeves CM, Stoltz BM. J Am Chem Soc. 2013; 135:17298. [PubMed: 24160327] . For related work with Mo and Pd, see: Braun M, Laicher F, Meier T. Angew Chem Int Ed. 2000; 39:3494.Chen JP, Ding CH, Liu W, Hou XL, Dai LX. J Am Chem Soc. 2010; 132:15493. [PubMed: 20945898] Trost BM, Dogra K, Franzini M. J Am Chem Soc. 2004; 126:1944. [PubMed: 14971921] Trost BM, Miller JR, Hoffman CM. J Am Chem Soc. 2011; 133:8165. [PubMed: 21534526] Trost BM, Zhang Y. J Am Chem Soc. 2006; 128:4590. [PubMed: 16594693] Trost BM, Zhang Y. J Am Chem Soc. 2007; 129:14548. [PubMed: 17985899] Zheng WH, Zheng BH, Zhang Y, Hou XL. J Am Chem Soc. 2007; 129:7718. [PubMed: 17539637]

5. Mahrwald, R. Modern Aldol Reactions. Wiley-VCH; Weinheim: 2004.

6. a) Kanayama T, Yoshida K, Miyabe H, Kimachi T, Takemoto Y. J Org Chem. 2003; 68:6197. [PubMed: 12895050] b) Kazmaier U, Zumpe FL. Angew Chem Int Ed. 1999; 38:1468.c) Huwig K, Schultz K, Kazmaier U. Angew Chem Int Ed. 2015; 54:9120.

7. Evans PA, Lawler MJ. J Am Chem Soc. 2004; 126:8642. [PubMed: 15250703] . For related work with a-hydroxy esters, see: Kiefer A, Gawas G, Kazmaier U. Eur J Org Chem. 2015:5810.

8. a) Ohmura T, Hartwig JF. J Am Chem Soc. 2002; 124:15164. [PubMed: 12487578] b) Kiener CA, Shu C, Incarvito C, Hartwig JF. J Am Chem Soc. 2003; 125:14272. [PubMed: 14624564]

9. We also investigated the reactions with metallacyclic catalyst generated in situ, with the pre-formed catalysts bearing different ligands, and at different temperatures. The reaction catalyzed by the preformed complex 3 at $5{ }^{\circ} \mathrm{C}$ or $0{ }^{\circ} \mathrm{C}$ afforded the product in the highest yield and $d r$. See Table S1 in SI for details. 
10. The solution of copper enolate was heterogeneous and was transferred into the vial containing allyl carbonate $\mathbf{2}$ and catalyst $\mathbf{3}$. The loss of $\mathrm{CuBr}$ was inevitable and unable to be measured. Considering the low price of $\mathrm{CuBr}$ and that inadequate amount of $\mathrm{CuBr}$ would result in lower diastereoselectivity in this reaction (Table 1, entry 11 versus entry 12), we decided to use excessive $\mathrm{CuBr}$ (2 equiv) as the additive for further study.

11. As observed for the test substrate $\mathbf{2 a}$ (see Table 1, entry 6 vs. entry 12), the reaction of 3,4-

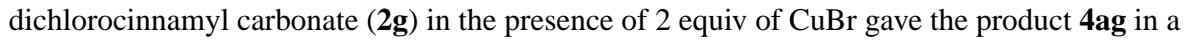
similar $91 \%$ yield, higher 15:1 dr, but slightly lower $89 \%$ ee than the reaction with 1 equiv of $\mathrm{CuBr}$ (see SI for details), whereas the same reaction with 0.5 equiv of $\mathrm{CuBr}$ resulted in similar yield (92\%), slightly lower $d r(12: 1)$, but excellent ee $(96 \%)$.

12. The reaction of 2-methoxyacetophenone with cinnamyl methyl carbonate afforded the product quantitatively with $d r$ of 1.9:1. It is possible that the initially formed product underwent epimerization under the reaction conditions to cause the dr of the final product to be low.

13. In several cases (4ca, $\mathbf{4 e a - 4 g a , ~} \mathbf{4 i c}, \mathbf{4} \mathbf{k m}$ ), viscous solutions of copper enolates were observed if 2 equiv of $\mathrm{CuBr}$ were added, and the consumption of limiting allylic carbonates was not completed within 12 hours. However, if less $\mathrm{CuBr}$ ( 1 or 0.5 equiv, see SI for details) was added, full conversion of the allylic carbonates was obtained within 12 hours.

14. Approximately $30 \%$ of allylic carbonate remained, and about $30 \%$ of the material was a mixture of uncharacterized products.

15. Seto H, Mander LN. Synth Commun. 1992; 22:2823. 

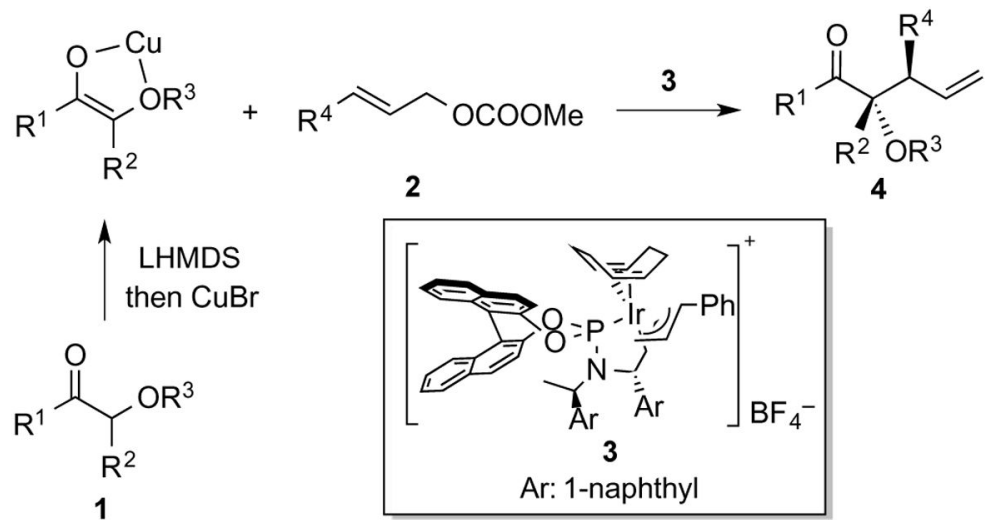

Scheme 1.

Iridium-catalyzed diastereo- and enantioselective allylations with unstabilized copper(I) enolates of acyclic a-alkoxy ketones. 

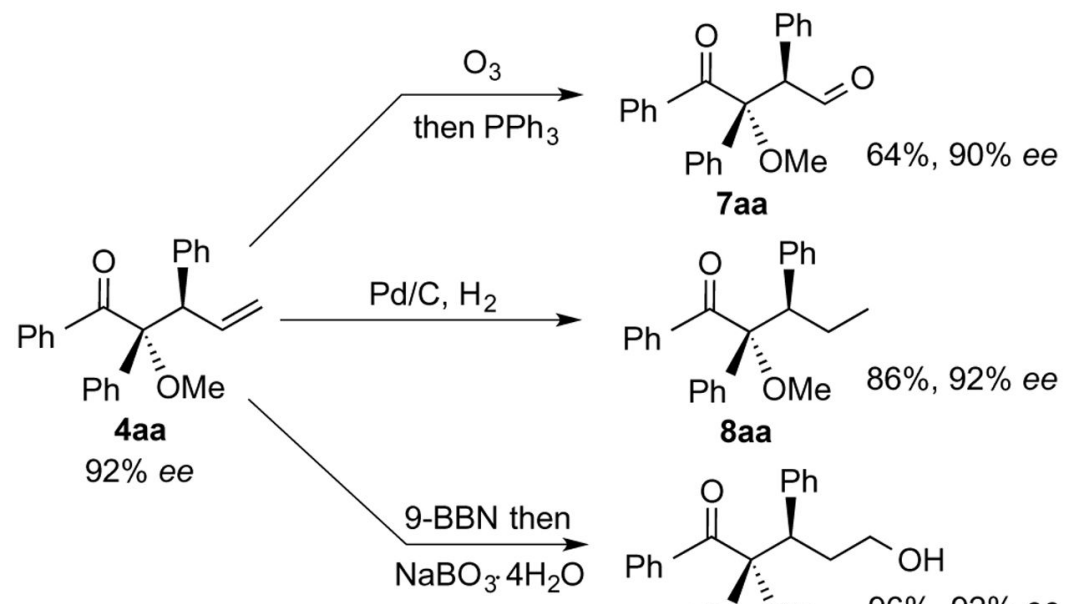

8aa

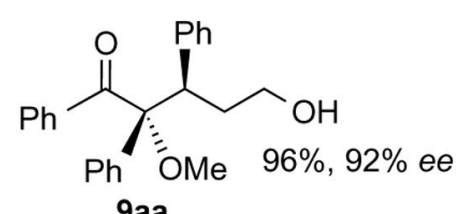

Scheme 2.

Derivatizations of 4aa. 


\section{Table 1}

Evaluation of reaction conditions for the Ir-catalyzed allylation. ${ }^{[a]}$

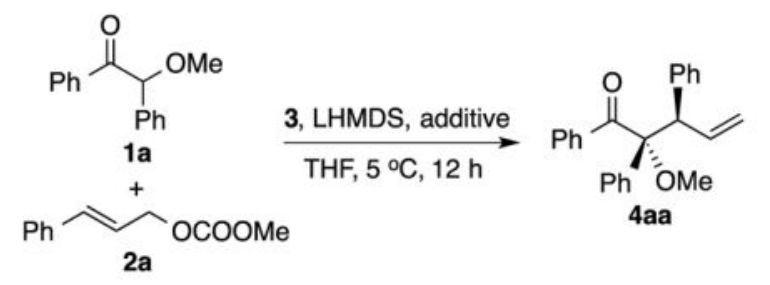

\begin{tabular}{ccccc}
\hline Entry & Additive & Yield [\%] $[\boldsymbol{b}]$ & $\boldsymbol{d r}_{\boldsymbol{r}}[\boldsymbol{c}]$ & $\boldsymbol{e e}[\boldsymbol{\%}]^{[\boldsymbol{d}]}$ \\
\hline 1 & - & 95 & $2.0: 1$ & n.d. \\
2 & $\mathrm{LiCl}$ & $>99$ & $1: 1.1$ & n.d. \\
3 & $\mathrm{ZnCl}_{2}$ & 72 & $16: 1$ & n.d. \\
4 & $\mathrm{CuI}$ & 97 & $5.7: 1$ & n.d. \\
5 & $\mathrm{CuCl}$ & 58 & $10: 1$ & n.d. \\
6 & $\mathrm{CuBr}$ & $>99(>99)$ & $14: 1$ & 92 \\
7 & $\mathrm{CuCN}$ & 34 & $2.5: 1$ & n.d. \\
8 & $\mathrm{CuOAc}$ & 52 & $1.5: 1$ & n.d. \\
9 & $\mathrm{CuSCN}$ & 94 & $2.3: 1$ & n.d. \\
$10^{[e]}$ & $\mathrm{CuBr}$ & 42 & $2.7: 1$ & n.d. \\
$11^{[f]}$ & $\mathrm{CuBr}$ & $>99$ & $14: 1$ & 93 \\
$12^{[g]}$ & $\mathrm{CuBr}$ & $>99$ & $12: 1$ & 95 \\
13 & $\mathrm{CuBr} 2$ & 0 & - & n.d. \\
\hline
\end{tabular}

${ }^{[a]}$ The molar ratio of $\mathbf{1} \mathbf{a} / \mathbf{2} \mathbf{a} / \mathbf{3} /$ LHMDS/additive $=2 / 1 / 0.02 / 2 / 2$. The absolute configuration of $\mathbf{4 a a}$ was assigned by analogy.

${ }^{[b]}$ Combined yield of two diastereoisomers. Determined by ${ }^{1} \mathrm{H}$ NMR analysis with mesitylene as internal standard. The yield in parentheses is an isolated yield of two diastereoisomers.

${ }^{[c]}$ Determined by ${ }^{1} \mathrm{H}$ NMR analysis of crude reaction mixtures.

${ }^{[d]}$ Determined by chiral SFC analysis of the major isomer.

$[e]$ KHMDS was used as the base instead of LHMDS.

$[f] 1$ equiv of $\mathrm{CuBr}$ was used.

${ }^{[g]} 0.5$ equiv of $\mathrm{CuBr}$ was used.

n.d. $=$ not determined. 


\section{Table 2}

Ir-catalyzed allylations of acyclic a-alkoxy ketone enolates: scope of allylic carbonates. ${ }^{[a]}$

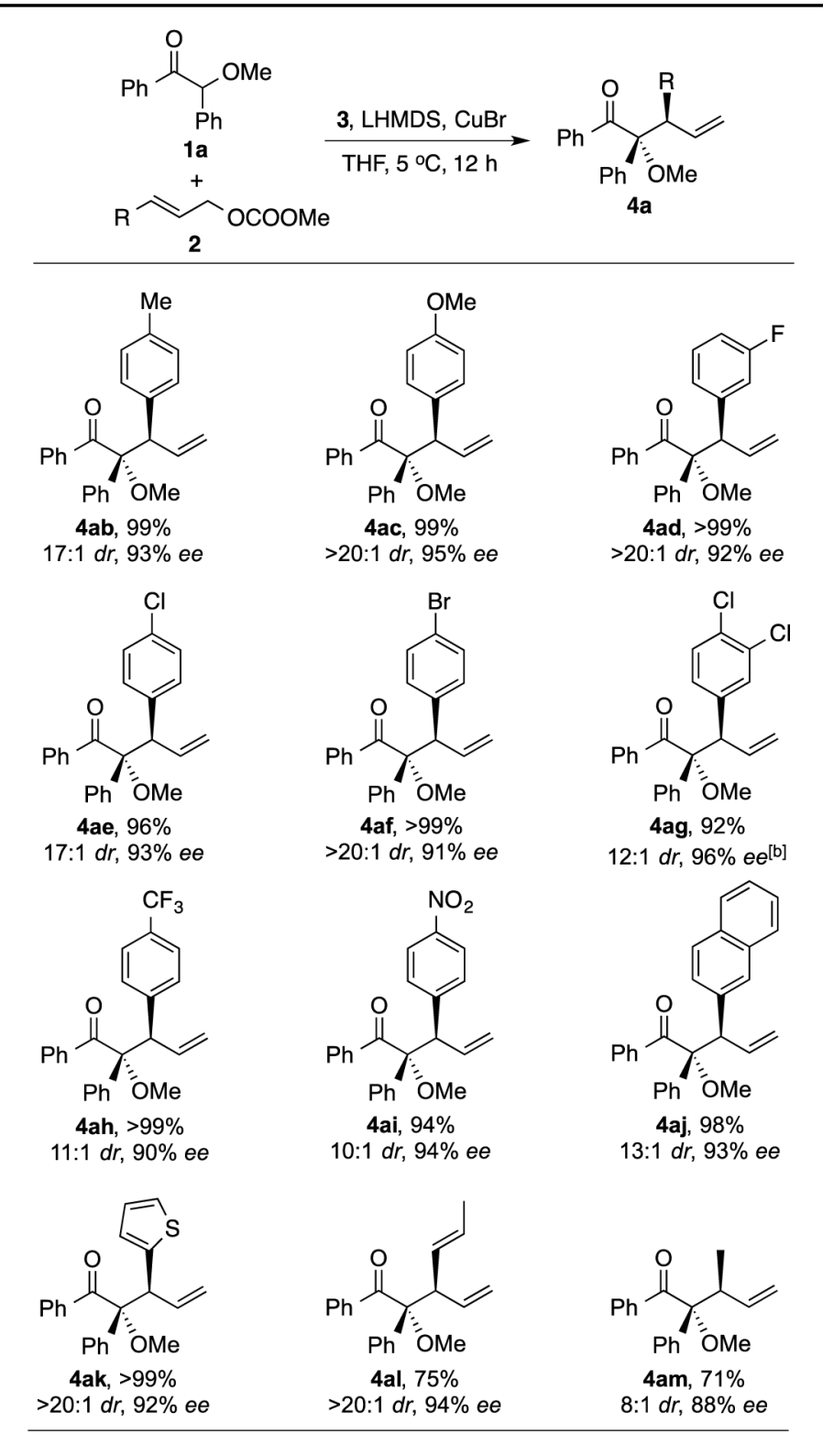

(1)

${ }^{[a]}$ The molar ratio of $\mathbf{1 a} / \mathbf{2} / \mathbf{3} / \mathrm{LHMDS} / \mathrm{CuBr}=2 / 1 / 0.02 / 2 / 2$. The absolute configurations were assigned by analogy. The structure of $\mathbf{4 a g}$ was determined by X-ray analysis. The yields were reported as the combined yields of two diastereoisomers. The diastereomeric ratios were determined by ${ }^{1} \mathrm{H}$ NMR analysis of crude reaction mixtures. The enantiomeric excesses were determined by chiral SFC analysis of major isomers.

${ }^{[b]} 0.5$ equiv. of $\mathrm{CuBr}$ was used. 
Table 3

Ir-catalyzed allylation of acyclic a-alkoxy ketone enolates: scope of ketones. [a]

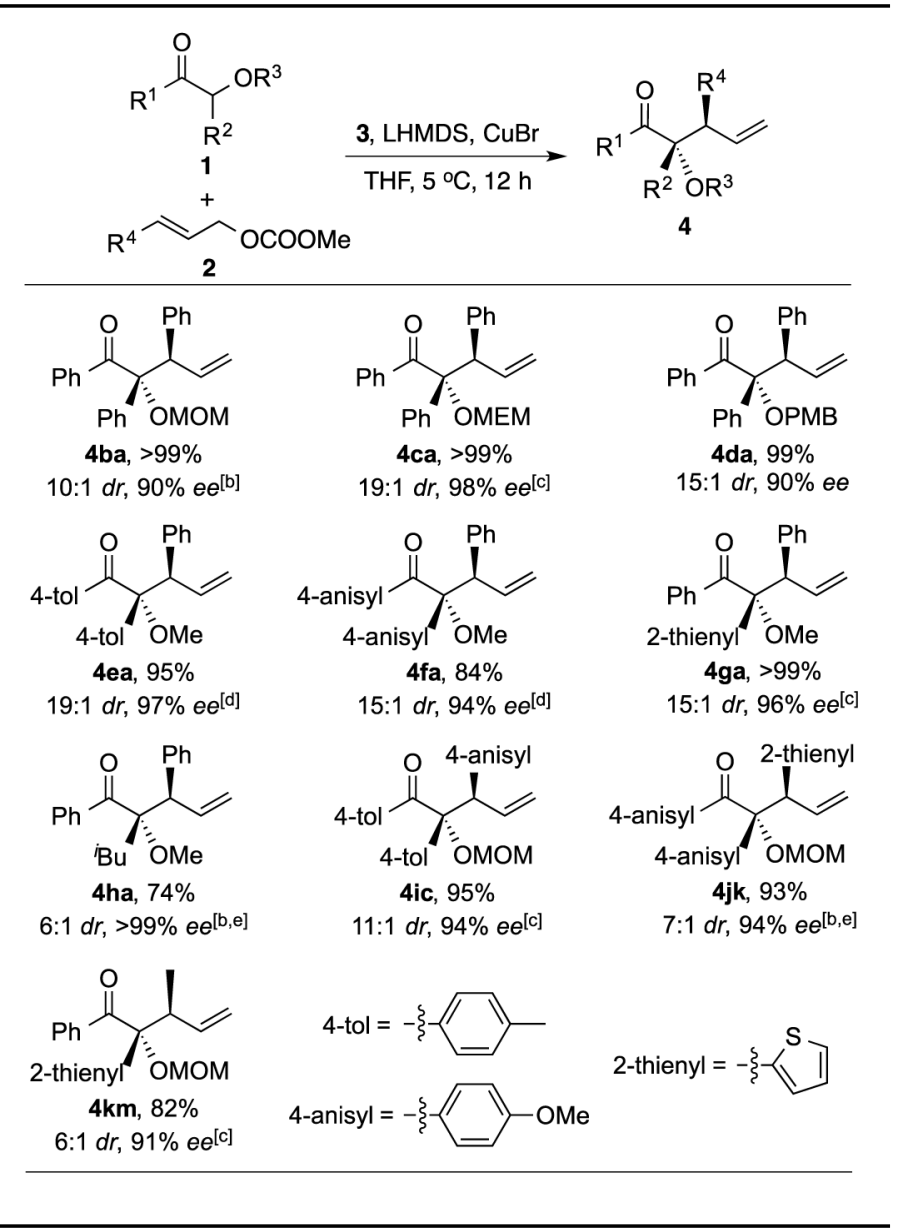

${ }^{[a]}$ The molar ratio of $\mathbf{1} / \mathbf{2} / \mathbf{3} / \mathrm{LHMDS} / \mathrm{CuBr}=2 / 1 / 0.02 / 2 / 2$. The absolute configurations were assigned by analogy. The yields were reported as the combined yields of two diastereoisomers. The diastereomeric ratios were determined by ${ }^{1} \mathrm{H}$ NMR analysis of crude reaction mixtures. The enantiomeric excesses were determined by chiral SFC analysis of major isomers.

${ }^{[b]} 4 \mathrm{~mol} \%$ of 3 was used.

$[c] 1$ equiv of $\mathrm{CuBr}$ was used.

${ }^{[d]} 0.5$ equiv of $\mathrm{CuBr}$ was used.

[e] cinnamyl acetate was used instead of cinnamyl carbonate, and the reaction time was elongated to $36 \mathrm{~h}$. The yield was reported as the isolated yield of the major diastereomer. 
Table 4

Synthesis of enantioenriched tertiary alcohols $\mathbf{5}$ and tetrahydrofuran derivatives $6 .{ }^{[a]}$

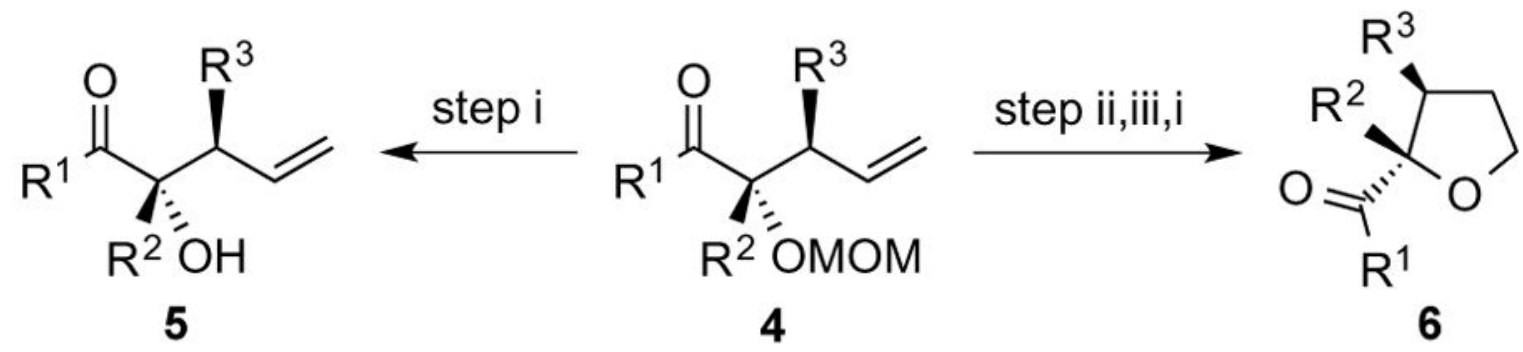<smiles>C=C[C@H](C)C(O)(C(=O)P)[C@@H](C)C=C</smiles>

$5 \mathbf{b a}$ $>99 \%, 90 \%$ ee<smiles>O=C(c1ccccc1)[C@]1(c2ccccc2)OCC[C@H]1c1ccccc1</smiles>

6ba
5 ic $>99 \%, 94 \%$ ee

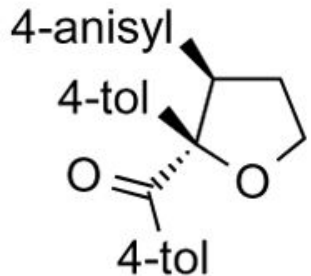

6ic $\mathbf{5 j k}$ $96 \%, 94 \%$ ee
$5 \mathbf{k m}$ $74 \%, 91 \%$ ee

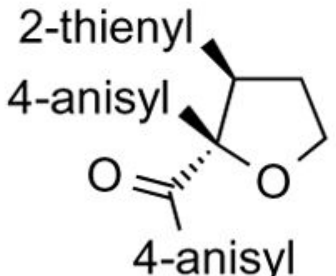

6jk<smiles></smiles>

$6 \mathrm{~km}$ $23 \%, 90 \%$ ee

$$
\text { 4-tol }=-\{-2 \text { 4-anisyl }=-\xi-2 \text {-thienyl }=-\xi-1
$$

\footnotetext{
${ }^{[a]}$ The yield for 6 is reported as the overall yield of 3 steps. The absolute structures were assigned by analogy. Steps: i) Dowex-50W-X8 $\left(\mathrm{H}^{+}\right.$form), $\mathrm{MeOH} / \mathrm{H}_{2} \mathrm{O}, 65^{\circ} \mathrm{C}$. ii) 9-BBN then $\mathrm{NaBO}_{3} \cdot 4 \mathrm{H}_{2} \mathrm{O}$. iii) TsCl, TEA.
} 